\title{
UNA VIDA SIN EXAMEN NO MERECE SER VIVIDA POR EL HOMBRE: VARIACIONES "SOCRÁTICAS" EN EPICTETO
}

\author{
Marcelo D. Boeri* \\ mboeri@uahurtado.cl
}

RESUMEN La presencia socrática en las Disertaciones de Epicteto es notoria, aunque no es del mismo modo claro qué es lo que reconoce como propiamente "socrático" de su propio pensamiento o qué ingredientes incorporó y desarrolló en el marco de su teoría moral y de su teoría de la acción. El propósito de este ensayo es mostrar cómo, a partir de un motivo "socrático" ("una vida sin examen no es vivible para el ser humano"; Platón, Apología de Sócrates 38a5-6), Epicteto desarrolla algunos aspectos cruciales de su ética y de su teoría de la acción, al traducir el dictum socrático como "hacer un uso correcto de las representaciones", lo único que garantizaría evitar tanto el error teórico como el práctico.

Palabras clave Epicteto; Sócrates; ética; teoría de la acción.

RESUMO A presença socrática nas Dissertações de Epicteto é notória, ainda que não é do mesmo modo claro o que é que ele reconhece como propiamente "socrático" em seu própio pensamento ou qual ingredientes incorporou e desenvolveu no marco de sua teoria moral e de sua teoria da ação. O propósito deste ensaio é o de mostrar como, a partir de un motivo "socrático" ("uma vida sem exame não é vivivel para o ser humano"; Platão,

* Professor de Filosofia Antigua na Universidad Alberto Hurtado, Chile. Este texto es un resultado parcial del proyecto Fondecyt 1085103 (Chile). Artigo recebido em 22/12/2010 e aprovado em 16/4/2011.

KRITERION, Belo Horizonte, nº 125, Jun./2012, p. 81-102. 
Apologia de Sócrates 38a5-6), Epicteto desenvolve alguns aspectos cruciais de sua ética e de sua teoria da ação, ao traduzir o dictum socrático como "fazer um uso correto das representações", o único que garantiria evitar tanto o erro teórico como o prático.

Palavras-chave Epicteto; Sócrates; ética; teoria da ação.

\section{Introducción: Epicteto el socrático}

Es difícil imaginarse la controversia que podía causar un filósofo como Sócrates que, a pesar de no haber escrito nada, suscitó reverencia en unos y rechazo en otros. Platón quedó completamente eclipsado por su figura, a punto tal que lo convirtió en el personaje central de varios de sus diálogos más importantes. Aristóteles, quien obviamente no lo conoció, tiene una visión más distante y, en algunos casos, fuertemente crítica de él. Pero ni siquiera Aristóteles, el primer gran crítico sistemático de algunas tesis socráticas, permaneció ajeno a algunas de las posiciones socráticas más contra-intuitivas.

Las conexiones entre Sócrates y los estoicos antiguos no han sido mayormente cuestionadas, aunque tales vínculos probablemente aún no han sido aclarados por completo. ${ }^{1}$ A pesar del estado fragmentario de los textos del estoicismo antiguo y medio, es seguro que los estoicos antiguos (Zenón, Cleantes y Crisipo) y Epicteto se consideraron a sí mismos como discípulos de Sócrates y reconocieron en él el modelo de persona sabia. ${ }^{2}$ Esto ha sido ampliamente reconocido por algunos destacados estudiosos y está muy bien

1 Una de las primeras estudiosas contemporáneas en enfatizar las conexiones entre Sócrates y los estoicos antiguos fue IOPPOLO 1980 (especialmente 70-79; 86-89); véase también LONG 1988 (reimpreso en su 1996; en adelante cito este artículo siguiendo la paginación de 1996). SEDLEY, por su parte, también ha subrayado la importancia de Sócrates para los estoicos al enfatizar que el trasfondo de la psicología estoica debería ubicarse en la psicología socrática más que en la platónica (véase su [1993], 313-314; 317318). Otros estudiosos también han señalado las conexiones entre Sócrates y los estoicos (cf. STRIKER 1994). El legado socrático ha sido analizado por LONG 1999: 617-641 y, más extensamente, por ALESSE 2000: 299-334.Cuando me es posible en la cita de los textos estoicos, remito a VON ARNIM1903-1905 (cito, como es habitual, con la sigla SVF, indicando volumen y número de texto), a A.A. LONG, D.N. SEDLEY 1987 (cito LS seguido de la sección y número de texto), y a k. HÜLSER 1987-1988 (cito con la sigla FDS seguida del número de texto).

2 Cito los textos de Epicteto por la edición del texto griego de SCHENKL 1965; las traducciones de los pasajes citados textualmente me pertenecen. Véase Epicteto, Disertaciones (en adelante Dis.), I 91 (donde atribuye a Sócrates la tesis del cosmopolitismo), I 9, 12-13 (donde atribuye a Sócrates la doctrina de los indiferentes, i.e. aquellos ítems que no son ni bienes ni males y que, por ende, no contribuyen en nada ni a la felicidad ni a la infelicidad del agente. Se trata de una tesis que tiene un antecedente socráticoplatónico importante; véase Eutidemo 281d; Gorgias 467e6-468a4). En Dis. IV 5, 1-4 Epicteto hace un reconocimiento explícito de Sócrates como modelo moral (citado por LONG 1996: 1-2). Para la presencia de Sócrates en las Dis. de Epicteto, véase LONG 1996: 2, n.2 y LONG 2002, cap. 3. 
atestiguado en las fuentes. ${ }^{3}$ A pesar de que es un hecho reconocido que la influencia de Sócrates en las escuelas helenísticas -y especialmente en los estoicos- fue mayormente a través de los cínicos, ${ }^{4} \mathrm{y}$ aun cuando, a mi juicio, no siempre es claro qué Sócrates debería considerarse como modelo de los estoicos -si el de Jenofonte o el de Platón-, me inclino a creer que en aquellos pasajes en los que puede detectarse una discusión teórica más refinada de la ética estoica el Sócrates platónico es el mejor candidato para ser considerado como una influencia positiva en los estoicos. ${ }^{5}$ En los restos fragmentarios del estoicismo antiguo encontramos tres tesis típicamente "socráticas" que están claramente documentadas y argumentadas en varios diálogos platónicos: $(i)$ la virtud es conocimiento (Menón 87c-d; Teeteto 176c), (ii) entre las virtudes hay unidad (Platón, Protágoras, 331e; 359b; 361a-b) -lo cual es reformulado por los estoicos en términos de su "implicación recíproca" ( $\left.\alpha \_\tau \alpha \kappa o \lambda o \cup \vartheta i ́ \alpha\right)$ de las virtudes-, y (iii) la virtud y la felicidad son lo mismo. ${ }^{6}$

Como he señalado, la presencia socrática en las Disertaciones de Epicteto es sin duda notoria, aunque no es del mismo modo claro qué es lo que reconoce como propiamente "socrático" de su propio pensamiento o qué ingredientes incorporó y desarrolló en el marco de su teoría moral y de su

3 Cf. LONG-SEDLEY 1987 (LS), vol.I, 383; STRIKER 1994: 241-251; DeFILLIPO-MITSIS, 1994: 252 ss., véase también SCHOFIELD, 1984: 83-96 y, más recientemente, LONG 1999.

4 LONG 1999: 620; 623. Sobre la influencia cínica en los estoicos cf. los textos reunidos por GIANNANTONI 1990, vol. II, V A, 135-140.

5 Hay, sin embargo, una importante presencia de la tradición socrática independientemente de la de Platón en el estoicismo (cf. Cicerón, Sobre la naturaleza de los dioses II 18; III 27; Sexto Empírico, Contra Matemáticos IX 98; Jenofonte, Recuerdos de Sócrates I 4, 5-18, citado y comentado por Long, quien ha llamado la atención sobre este pasaje en su 1996: 20-23. De hecho es éste uno de los pocos textos que nos permitirían pensar en Sócrates como en un predecesor de la tesis estoica de que los principios de la moralidad pueden derivarse de las leyes que gobiernan el mundo natural (cf. Plutarco, Sobre las contradicciones de los estoicos [Contrad.], 1050-b). Para una discusión del texto de Jenofonte recién citado véase DeFILLIPO-MITSIS 1994: 253-255. Sería posible, sin embargo, que Jenofonte, a su vez, haya sido influenciado por Antístenes, como lo muestran los varios pasajes en los que Jenofonte cita tesis de Antístenes (como la de que la riqueza o la pobreza reside no en la casa de uno, sino en su alma; Simposio, IV 34= GIANNANTONI 1990, vol. II, V A 82). Es muy probable que los estoicos no hayan tenido "el problema de Sócrates" (LONG 1996: 4-5) y que no hayan distinguido claramente entre los textos históricamente socráticos y los textos platónicos (SEDLEY 1993: 314). Eso se ve ya en los autores de la antigüedad que constituyen fuentes importantes del estoicismo antiguo: Galeno, al comentar la explicación de Crisipo de la debilidad del alma del vicioso, atribuye la tesis de que nadie yerra voluntariamente a Platón, no a Sócrates (Sobre las doctrinas de Hipócrates y Platón [DHP], p. 272, 36-274, 1, ed. DE LACY). La mejor discusión de conjunto de Galeno como fuente de la psicología estoica sigue siendo, a mi juicio, la de FILLION-LAHILLE 1984. Su tesis de que Posidoniono rechazó el monismo psicológico de Crisipo y de que lo que Posidonio hizo fue una reelaboración progresiva de una misma doctrina, "siempre fiel a sus principios y firme en sus grandes líneas" (1984: 122-123) ganó varios adeptos entre los intérpretes (cf. GILL 1998; COOPER 1999: 451-455; 467-468).

6 Véase Estobeo, Extractos de física y ética (Ext.; cito por el número de página y línea de la ed. de WACHSMUTH), II 59, 4-60, 80; 63, 6-10; Galeno, DHP p. 434-436, ed. DE LACY(SVF III 256); Diógenes Laercio [DL] VII 87. Para una interpretación de conjunto de las posiciones socráticas cf. GÓMEZ-LOBO 1998 y BRICKHOUSE-SMITH 2000. 
teoría de la acción. En este ensayo me propongo mostrar cómo, a partir de un motivo "socrático" ("una vida sin examen no es vivible para el ser humano"; Platón, Apología de Sócrates 38a5-6), Epicteto desarrolla algunos aspectos cruciales de su ética y teoría de la acción. ${ }^{7}$ En la reinterpretación que Epicteto hace de esta sentencia socrática la misma es traducida como "hacer un uso correcto de las representaciones", lo único que garantizaría evitar tanto el error teórico como el práctico, ya que la recomendación socrática de no vivir una vida sin examen es, en opinión de Epicteto, lo mismo que no aceptar una representación sin examen. En el contexto de su teoría de la acción tal afirmación significa no prestar asentimiento a una representación sin haberla

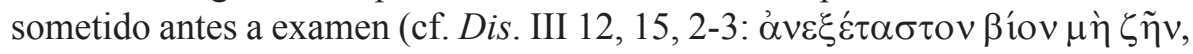

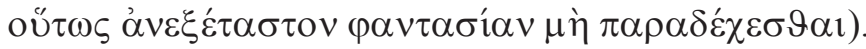

\section{La imposibilidad de vivir una vida sin examen y el uso correcto de las representaciones}

Como he indicado recién, Epicteto traduce la sentencia socrática, según la cual una vida sin examen no es vivible para un ser humano, como no aceptar una representación que no haya sido sometida a examen (Dis. III 12, 15, 2-3), lo cual es lo mismo que hacer un uso correcto de las representaciones. Una vida buena, es decir, una vida humana de buena calidad supone, en opinión de Epicteto, el ejercicio de una facultad que, como la capacidad impulsiva

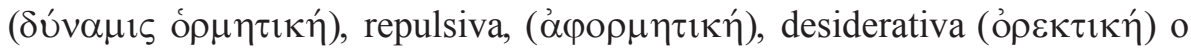

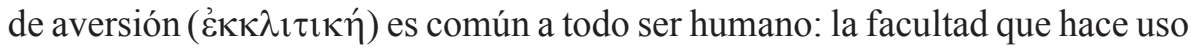

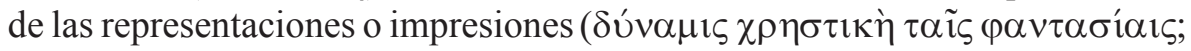
Dis. I 1, 12). Según Epicteto, si uno cuida de esta facultad y pone todo lo de

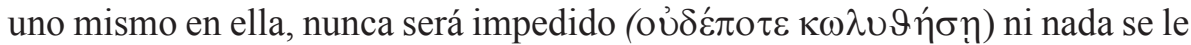

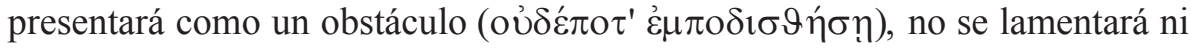
censurará, ni tampoco adulará a nadie (Dis. I 1, 13). En suma, el uso correcto de la facultad de hacer uso de las representaciones parece garantizar la completa autosuficiencia del agente racional y una vida humana de buena calidad. ${ }^{8}$

7 El pasaje de la Apología platónica es parafraseado por Epicteto en Dis. I 26, 18, 1 y III 12, 15, 2 como "Sócrates hablaba de no vivir una vida sin examen". Con "Sócrates" o "socrático" me refiero especialmente al "Sócrates platónico", cuyas tesis y argumentos pueden ser reconstruidos especialmente a partir de algunos diálogos tempranos de Platón (tales como Protágoras, Gorgias, Menón, Laques, Eutidemo y, tal vez, el libro I de la República). Para una defensa de este punto de vista y de la posibilidad de seguir hablando de "investigaciones socráticas" cf. el reciente libro de BRICKHOUSE-SMITH 2010 (especialmente cap. 1).

8 El uso correcto de nuestras representaciones es, según Epicteto, lo único que depende de nosotros (Dis.I 1, 7-9). Véase también II 18, 24-32, donde es claro que pretende enfatizar que no depende del agente la $\varphi \alpha v \tau \alpha \sigma i \alpha$, sino el examen que uno haga de ella: "Espérame un poco, representación; permíteme ver 
Son abundantes los pasajes en los que Epicteto enfatiza el hecho de que, aunque el dios ha dotado de razón a todos los seres humanos, es solamente el filósofo quien se propone hacer un uso adecuado de su racionalidad para descubrir el bien y el mal. En efecto, Epicteto sostiene que los humanos hemos

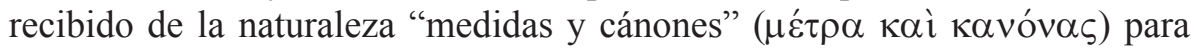
descubrir la verdad; no obstante, solemos hacer exactamente lo contrario de lo que tales medidas y cánones nos indican. ${ }^{9}$ Esto, en cierto modo, significa que un agente racional es capaz de hacer elecciones alternativas: la naturaleza o dios nos ha dotado de racionalidad y en parte es nuestra propia responsabilidad desarrollar apropiadamente dicha racionalidad. En efecto, los dioses han dotado a los seres humanos de una cierta porción de sí mismos, esto es, la facultad de elegir o rechazar algo, o más específicamente, la posibilidad de elegir o rechazar un curso determinado de acción. Esa facultad de elegir es identificada con la facultad de hacer un uso (correcto) de las representaciones (Dis. I 1, 7-13). Si ése no fuere el caso, no sería posible distinguir una representación verdadera de una falsa y, consecuentemente, tampoco sería posible "descubrir la verdad", que, desde el punto de vista de Epicteto, significa conocer la "esencia del bien" y actuar en conformidad con él. ${ }^{10}$

Obviamente, no hay ningún pasaje en los textos socrático-platónicos en los que encontremos desarrollos como los que acabamos de discutir como probables explicaciones de la tesis socrática, según la cual una vida sin examen no es digna de ser vivida por un ser humano. Sin embargo, hay al menos un pasaje en el Menón platónico que puede haber servido de inspiración a Epicteto en su tesis de hacer un "uso correcto" (de las representaciones):

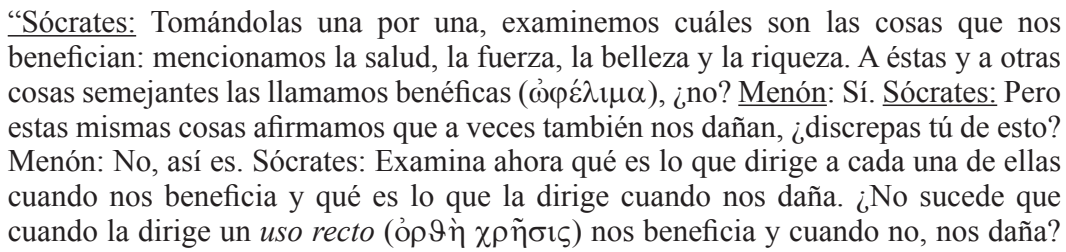

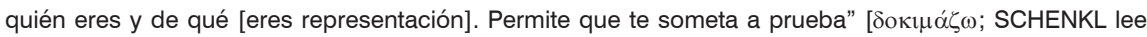
$\delta о к ц \alpha ́ \sigma \omega]$; II 18, 24-25. El que es capaz de hacer esto es quien se ejercita verdaderamente en relación con sus representaciones (II 18,27).

9 Cf. Dis. II 20, 21-22 con el comentario de IERODIAKONOU 2007: 59-60.

10 Para una discusión pormenorizada de este importante detalle cf. DRAGONA-MONACHU 2007: 122-123.

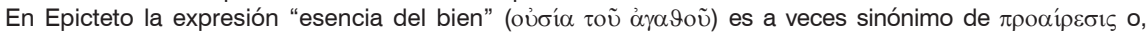

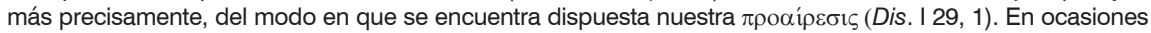

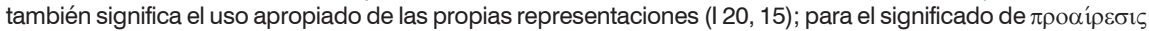
en Epicteto (a veces "arbitrio", en el sentido de la determinación que posee el agente en la elección de un curso de acción, o también del yo) y las dificultades de su traducción cf. LONG 2002: 28-30. 
[...] La riqueza y las demás cosas de esa índole, de las que acabamos de decir que a veces son buenas y a veces dañinas, ¿no ocurre que tal como la prudencia al dirigir el resto del alma hacía benéficas las cosas del alma y la necedad las hacía dañinas, así también si el alma las usa y dirige rectamente las hace benéficas y si lo hace incorrectamente, dañinas?" (Platón, Menón 87e5-88a5; 88d4- e2; trad. A. GÓMEZLOBO 2004).

En el contexto es claro que lo que Platón se propone mostrar es que "bienes" (condicionales), tales como riqueza o belleza, solamente pueden ser verdaderos bienes si son usados correctamente, es decir, si son usados con criterios racionales correctos bajo los dictados de un "alma sabia o prudente" (Menón 88e3-4). También sugiere que algo similar puede ocurrir con la valentía (o, en realidad, con una supuesta valentía que en rigor no lo es): si la valentía no es prudencia, sino una cierta osadía ( $\vartheta \alpha ́ \rho \rho o \varsigma)$, una persona osada o audaz que actúa sin inteligencia (voũs) sufre un daño, no un beneficio (lo mismo puede ocurrir en relación con una supuesta forma de moderación desprovista de inteligencia). Ahora bien, dada la identidad (declarada por

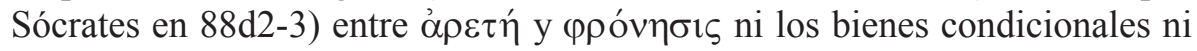
los estados anímicos más o menos similares a genuinas excelencias pueden ser verdaderos bienes. En cualquier caso, la explicación es efectiva para mostrar que, si un ítem carece de conocimiento o de un criterio racional que garantice su uso correcto, no califica como un verdadero bien, además del hecho de que dicho conocimiento es una propiedad del alma.

Aunque no hay forma de probar que este pasaje del Menón (o algún otro similar de otro diálogo platónico) es el que efectivamente haya inspirado la tesis epictetea sobre el uso correcto de las representaciones, es relativamente claro que la tesis platónica respecto de la necesidad de contar con un conocimiento para ser capaz de hacer un uso correcto de algo es incorporada sin discusión por Epicteto a su modelo explicativo de la acción. Dado que es inevitable que todo individuo haga uso de cada cosa de acuerdo con lo que supone o cree sobre ella (Dis. I 3, 4-6; II 11, 14-15), pero puesto que el propio juicio no puede ser, ni siempre ni en todos los casos, el criterio, urge explicar cómo las propias creencias - que pueden ser falsas y, por ende, no califican como verdaderos criterios- pueden ser el punto de partida de un "uso correcto de las representaciones". ${ }^{11}$ Es habitual en Epicteto enfatizar el hecho de que el humano, por el solo hecho de estar dotado de racionalidad y comprensión, es capaz de progresar hasta el punto en que sus representaciones su parecer obviamente no puede ser un criterio confiable de su acción (II 11, 12). 
y su asentimiento sean completamente racionales y virtuosos (cf. Dis. I 4, 18-21). Hay un sentido en que ninguna representación puede ser "virtuosa" pues, en rigor, no depende del agente; no obstante, Epicteto está dispuesto a mostrar que lo que se le representa al agente es la medida de su acción

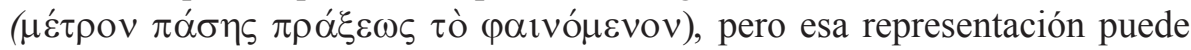

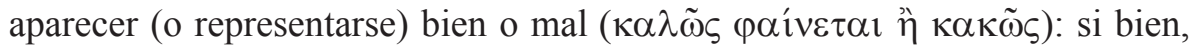
el agente no es culpable, si mal el agente mismo recibe el castigo (Dis. I 28, 10). Esta idea, probablemente socrática en su origen, es que lo decisivo reside en el estado cognitivo del agente y en el tipo de creencias que de tal estado cognitivo se siguen: si el estado epistémico propio de mi alma es conocimiento lo que se me representa como correcto es digno de mi asentimiento porque es efectivamente correcto. Si mi estado cognitivo es ignorancia lo que se me representa como bueno no lo será y el prestarle asentimiento dará lugar al error práctico. El argumento evoca la tesis socrática de que para neutralizar el poder de la apariencia e intentar distinguir apropiadamente el bien aparente del bien real el agente debe procurar fortalecer o refinar sus capacidades cognoscitivas $\mathrm{y}$, junto con ellas, sus estados caracterológicos. ${ }^{12}$

Como es obvio, los desarrollos de Epicteto sobre el uso correcto de las representaciones no pueden inferirse de una manera particularmente obvia a partir de la sentencia socrática, según la cual una vida sin examen no es digna de ser vivida para un ser humano, pero ése es el modo en que sin duda entendió dicha sentencia Epicteto y, al menos en cierto sentido, su comprensión de la misma parece exhibir varios ingredientes ciertamente "socráticos": (i) el conocimiento que es la virtud o excelencia moral no debe entenderse como un conocimiento puramente intelectual que no tenga conexión con la acción. (ii) El examen de las representaciones, por ende, no es solamente relevante para no cometer un error teórico, sino fundamentalmente para evitar el error práctico. Como veremos enseguida en el siguiente apartado, Epicteto parece estar particularmente preocupado por las representaciones cuyo asentimiento dan lugar a una acción. Dicho de otro modo, parece que el énfasis práctico en la expresión "uso correcto de las representaciones" es decisivo. Hay claramente un sentido en el que uno siempre podría pensar que con "uso" ( $\chi \rho \tilde{\eta} \sigma ı \varsigma_{\text {) }}$

12 Para este enfoque socrático cf. Platón, Protágoras 356d3-e2. Se trata de una tesis que también Aristóteles incorpora a su explicación de la acción cuando en Ética Nicomaquea III 5 procura mostrar que si cada uno es responsable de su propio estado del carácter, también debe ser, en cierto modo, responsable, de cómo algo $x$ se le aparece o representa como siendo bueno (1114a31-b3; para una discusión detallada de este tema en Aristóteles y sus conexiones con los estoicos me permito remitir a BOERI 2004: 131-134). Dicho de otro modo, el fin (que coincide con el bien) se le representa a cada uno de un modo que corresponde con su propio estado del carácter. 
Epicteto sólo puede pensar en lo que tal expresión significa en el dominio práctico: "usar" las representaciones es "tratar" con ellas de tal manera que el resultado de dicho trato o uso dé lugar a un estado de cosas que compromete la vida práctica: debemos preparar del mejor modo posible lo que depende de nosotros y usar $(\chi \rho \tilde{\gamma} \sigma \vartheta \alpha \iota)$ lo demás tal como es por naturaleza (Dis. I 1, 17). "Preparar del mejor modo posible lo que depende de nosotros" es preparar de manera óptima nuestra facultad de usar apropiadamente las representaciones (que es lo único que en rigor depende de nosotros), y "usar lo demás tal como es por naturaleza" significa, como el propio Epicteto aclara, hacerlo "como el dios quiere". Esto es, hacer lo apropiado a la propia naturaleza: algunas cosas han sido producidas por dios con un propósito, otras con otro. El dios precisaba de los animales como de criaturas que hicieran uso de sus representaciones, y de los humanos como de quienes fueran capaces de comprender ese uso. En

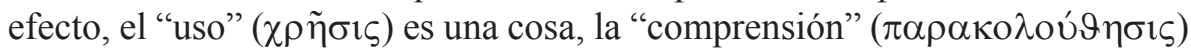
de dicho uso, en cambio, es otra. Es por eso que a los demás animales les basta con comer, beber y llevar a cabo otras funciones que corresponden a su naturaleza. Pero para los humanos, a quienes el dios ha dotado de la facultad de comprender ( $\pi \alpha \rho \alpha \kappa \circ \lambda \circ \cup \vartheta \eta \tau \iota \kappa \eta ̀ ~ \delta u ́ v \alpha \mu \iota \varsigma)$, ese tipo de funciones no es suficiente (cf. Dis. I 6, 13-17). No es, entonces, que los irracionales no hagan uso de las representaciones o incluso de que, hasta cierto punto, hagan un uso correcto de sus representaciones cuando, por ejemplo, distinguen la comida de la bebida. Pero el uso correcto de las representaciones que Epicteto está interesado en acentuar es el que presupone un uso comprensivo y práctico de las representaciones, el único que garantizaría alcanzar de manera apropiada el fin humano, que reside en la contemplación y la comprensión que da lugar al modo de vida que está en armonía con la naturaleza (Dis. I 6, 20-21)

Como es claro en el pasaje socrático de Apología 38a que Epicteto entiende en términos de "uso correcto de las representaciones", el examen en que debe consistir una vida humana de buena calidad no es más que examinar racionalmente lo que se refiere a la excelencia o perfección humana. El talante "práctico" de este tipo de énfasis es conservado y ampliado por Epicteto con el desarrollo de una teoría de la acción que presupone la doctrina estoica del asentimiento.

\section{Uso correcto de las representaciones y asentimiento}

Según la versión estoica más o menos ortodoxa, el asentimiento

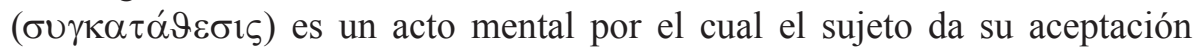
al contenido intencional de una representación, i.e. acepta como verdadero 
el contenido de la representación; aunque asentimiento y representación pueden entenderse como dos acontecimientos diferentes que suceden en la mente, en algunos casos su relación es muy estrecha. ${ }^{13}$ Hay casos en los que el asentimiento a un cierto tipo de representación da lugar a la acción, i.e. aquellos casos en los que el asentimiento lo es a una "representación motivante

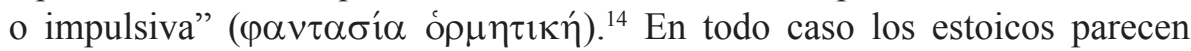
haber distinguido claramente el objeto del asentimiento: las proposiciones (que constituyen el contenido intencional de las representaciones; cf. Estobeo, Ext. II 88, 2-6; SVF III 171; LS 33I) y también parecen haber argumentado que el asentimiento depende del agente. ${ }^{15}$ Esto último es particularmente enfatizado por Alejandro de Afrodisia (Sobre el destino 178, 17-28), quien hace especial hincapié en el hecho de que el ser humano, a diferencia de los animales, no sigue sus representaciones irreflexivamente, sino que su propia naturaleza lo ha dotado de razón, la cual lo faculta a decidir qué es elegible y que no lo es (como es obvio, se trata en este caso del asentimiento que se presta a una representación evaluativa pues dicha representación se le aparece

13 En mi interpretación de la psicología estoica de la acción estoy sugiriendo que asentimiento e impulso son eventos diferentes (para una lectura distinta, que identifica asentimiento e impulso, cf. BRENNAN 2003: 265-268). El asentimiento es un tipo de acto cognitivo que implica el reconocimiento de que la proposición (que, según los estoicos, es la representación) es verdadera, en tanto que el impulso es un movimiento hacia la realización de la acción que el agente considera apropiada. La cuestión es muy controvertida y los textos muy escasos: uno podría pensar que asentimiento e impulso son una única totalidad en la medida en que el impulso inmediatamente convierte en acción el predicado de la proposición, y esto ocurre cuando la proposición ha sido reconocida como verdadera. Para la discusión de esta espinosa cuestión véase también INWOOD 1985: 60-62 y IOPPOLO 1995: 27-28. El escéptico Arcesilao (citado por Sexto

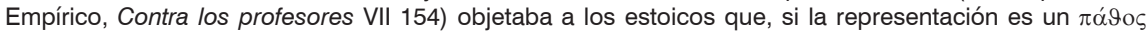
que se da en el alma, el sujeto no puede dar asentimiento a la representación, sino a una proposición; esta objeción, en realidad, no genera ninguna dificultad a los estoicos pues expresamente admiten que el asentimiento lo es a las proposiciones (cf. Estobeo, Ext. II 88, 1-6) y que la $\varphi \alpha v \tau \alpha \sigma i ́ \alpha$ es una proposición (cf. Sexto, Contra los profesores VII 242; 306-307; 312-313). Incluso Marco Aurelio sigue pensando que una representación es una proposición (cf. V 16, donde un argumento es un buen ejemplo de $p \alpha v \tau \alpha \sigma i ́ \alpha)$.

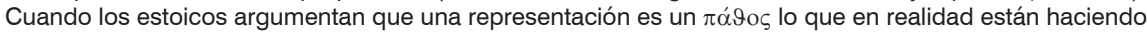
es enfatizar su aspecto fisiológico; pero las $\varphi \alpha \nu \tau \alpha \sigma i ́ \alpha$ ı estoicas también tienen un aspecto intencional, razón por la cual pueden identificarse con proposiciones.

14 Estobeo, Ext. II 86, 17-18 (SVF III 169, 171, 173; LS 53Q, 33I); sobre la "representación impulsiva" como el tipo de representación cuyo asentimiento da lugar a un impulso y a una acción cf. también Orígenes, Sobre los principios III 1, 2, 11-12: "las cosas animadas se mueven por sí mismas cuando [en ellas] sobreviene una

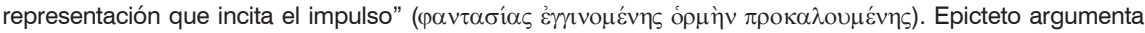

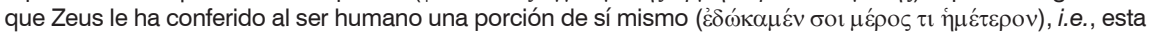

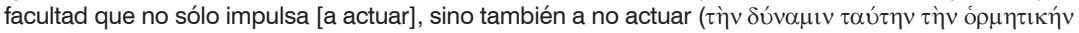

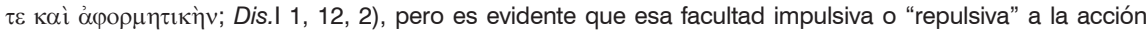
presupone como paso previo un acto de asentimiento (cf. I 14, 7, 3-6; I 21, 2). Sobre la recomendación de Epicteto de no prestar asentimiento más que a una representación cognitiva cf. III 8, 4, 2-5, 1 (véase también III 12, 14, donde el asentimiento es entendido como una actividad racional crítica que no da por cierta una representación sin someterla a examen).

15 Clemente de Alejandría, Misceláneas II 12, 54, 5-55, 1 (SVF II 992; FDS 365). Cf. también Epicteto, Dis. III 7, 14-15. 
al agente como algo elegible). La razón, en efecto, "somete a prueba" las representaciones antes de que el sujeto les preste su asentimiento. ${ }^{16}$

En conexión con esta caracterización de asentimiento pueden leerse tres importantes pasajes de Epicteto, ${ }^{17}$ que introducen el interesante problema de que nadie asiente voluntariamente a lo falso, revelando de nuevo un importante ingrediente "socrático-platónico" del pensamiento epicteteo: nadie cree que lo que cree es falso (cf. Platón, Teeteto 171b4; 200a3; Sofista 228c). Siempre que uno presta su asentimiento lo hace porque cree que la proposición es verdadera; lo que puede ocurrir, como señala Epicteto, es que uno crea o le parezca que lo falso es verdadero. Es por eso que uno no puede creer que algo le conviene y no elegirlo; el caso de Medea ilustra, según Epicteto, el asunto: Medea cree que es más conveniente para ella castigar a su marido, no importa que eso presuponga asesinar a sus hijos. Lo que puede suceder es que la creencia que motiva esa elección sea falsa, de donde se sigue que tomará por verdadero lo que en realidad es falso. Éste es el caso del "ruin" o "inferior" ( $\varphi \alpha \tilde{u} \lambda \circ \varsigma)$ estoico; uno podría argumentar de un modo conservadoramente estoico que todo lo que se le presenta a un $\varphi \alpha \tilde{u} \lambda o \varsigma$ estoico es susceptible de $\mathrm{su}$ asentimiento como si fuera real (i.e. verdadero), pues es un sujeto cuyo asentimiento es siempre precipitado. ${ }^{18}$ Como ya he adelantado, los estoicos sostienen que para que el asentimiento a una representación dé lugar a un impulso y a la acción correspondiente, tal representación debe ser "motivante" o "impulsiva” ( $\varphi \alpha \nu \tau \alpha \sigma i ́ \alpha$ ó $\rho \eta \tau \imath \kappa \eta ́) .{ }^{19} \mathrm{El}$ asentimiento a una representación que no es impulsiva (como "mi mano tiene cinco dedos") no da lugar a una acción; la idea estoica es que cualquier agente racional, sabio o no sabio, obra sobre la base de una "representación de lo debido"; pero para que la representación motivante o impulsiva sea cognitiva (es decir, verdadera, proveniente de "lo que es" o "lo que es el caso", y que describe una cosa o estado de cosas como exactamente es; DL VII 45-46; SVF II 53; LS 40C; FDS

16 Un comentario más detallado de este importante pasaje de Alejandro puede verse en SALLES 2005: 5758.

17 Epicteto, Dis. I 28, 4 (cito y trato en detalle este pasaje más abajo); III 7, 14-15; III 22, 42-43.

18 Cf. DL VII 46; Estobeo, Ext. II 112, 5-7 (SVF III 548). El sabio, en cambio, se caracteriza por tener "no

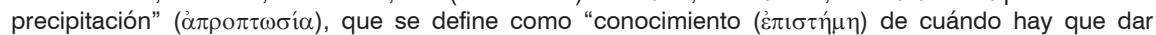
asentimiento y de cuándo no hay que darlo". Véase las observaciones de GÖRLER 1977: 85-86 sobre la definición de "no precipitación" como "la disposición de no dar asentimiento antes de tener una cognición" (cf. SVF II 131=Papyrus Herc. 1020). Véase también Epicteto, Dis.II 8, 29: “Les mostraré el

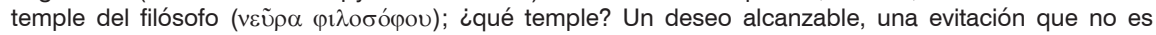
inevitable, un impulso apropiado, un propósito cuidadoso, un asentimiento no precipitado". Para un análisis pormenorizado del asentimiento precipitado en Epicteto véase SALLES 2007: 251-255.

19 Cf. Estobeo, Ext.II 86, 17-87, 5; SVF III 169; LS 53Q.Véase también Orígenes, Sobre los principios III 1, 2-3; SVF II 988. Cicerón, Cuestiones Académicas II 24-25. 
33) debe ser garantía de la verdad (en este caso práctica), ya que si el agente le presta su asentimiento el resultado será un acto virtuoso.

Epicteto ofrece una explicación importante al respecto: la premisa inicial del argumento es que todo error o acto incorrecto $(\alpha \mu \alpha \dot{\rho} \tau \eta \mu \alpha)$ implica un conflicto o contradicción ( $\mu \alpha \dot{\chi} \chi \eta)$, seguramente entre lo que cree el agente de algo y lo que ese algo efectivamente es el caso. Pero el que está en el error no quiere (ni cree) estarlo, sino que cree que actúa correctamente. De donde se sigue la conclusión de que el que está en el error no hace lo que (en realidad) quiere (Dis. II 26, 1). El argumento tiene un tono fuertemente intelectualista y, una vez más, recuerda un argumento similar del Sócrates platónico. ${ }^{20}$ Epicteto ensaya un segundo argumento: $(i)$ toda alma racional es por naturaleza contraria al conflicto o a la contradicción; sin embargo, (ii) no hay nada que a un agente le impida llevar a cabo "acciones conflictivas o contradictorias" ( $\tau \grave{\alpha} \mu \alpha \chi o ́ \mu \varepsilon v \alpha \pi o 1 \varepsilon \tilde{\imath} v),{ }^{21}$ a menos que ignore que las está llevando a cabo. Pero (iii) habiendo advertido ( $\pi \alpha \rho \alpha \kappa \circ \lambda \circ \vee \vartheta \eta ́ \sigma \alpha \nu \tau \alpha)$ que está llevando a cabo acciones conflictivas, renuncia y evita tal conflicto. De donde se sigue

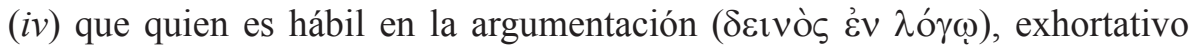
y capaz de refutar es el que le muestra a cada uno el conflicto que le está causando su error, i.e. le hace ver que no lleva a cabo lo que en realidad quiere, sino que hace lo que en realidad no quiere. Pero nadie puede salir del error a menos que se le haga evidente que lo que está haciendo no es en realidad lo que le conviene ni lo que quiere (porque nadie quiere lo que es malo para sí mismo). Hasta tanto no ocurra esto el agente permanecerá firme en su error

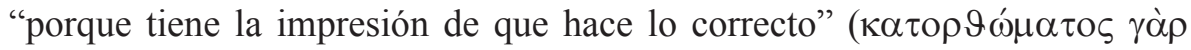

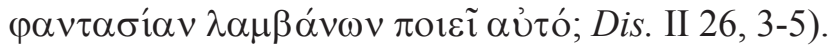

El argumento es importante para mostrar, una vez más, que es el asentimiento a una representación impulsiva de lo debido o correcto la que pone en movimiento al agente como tal; también es relevante para mostrar que, hasta que el agente no adquiera un cierto esclarecimiento cognitivo, será incapaz de prestar su asentimiento a la representación práctica correcta, sino que seguirá prestándolo a la representación práctica incorrecta, aunque creyendo que lo presta a una representación correcta. Uno podría preguntarse por qué, aunque se le presente una representación correcta, el vil estoico no

20 Cf. Platón, Gorgias 468b1-e5; 494c4-495c2; 499e8-9; 506c4-507d2.

21 Estas acciones "contradictorias o conflictivas" probablemente deben entenderse en el sentido de las acciones que van en contra de los verdaderos intereses y deseos del agente, porque todo ser racional dice la premisa socrática que Epicteto hace suya- quiere y persigue lo que es bueno o, más precisamente, lo que cree que es bueno. El problema es que puede estar equivocado en creer que algo que persigue como un bien sea, efectivamente, un bien. 
asiente a ella; tal vez la respuesta estoica más razonable sería que uno reconoce tal representación y asiente a ella si y sólo si tiene conocimiento; si tiene opinión no la reconoce en un sentido cabal, pues reconocerla en un sentido cabal es asentir a ella toda vez que se hace presente. Lo que he discutido

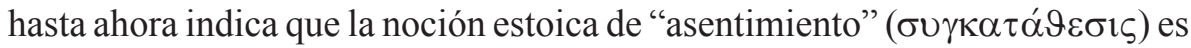
lo suficientemente amplia como para desempeñar un papel significativo tanto en la epistemología como en la ética y la teoría de la acción. Como ya he señalado, la acción se sigue del impulso que, a su vez, resulta del asentimiento a la representación impulsiva. La acción es un movimiento corpóreo que presupone algún tipo de intención por parte del agente; en cuanto movimiento intencional una acción presupone un impulso (óp $\mu$ ท́) previo y, por lo tanto, algo que lo ponga en movimiento, a saber, una "representación impulsiva".

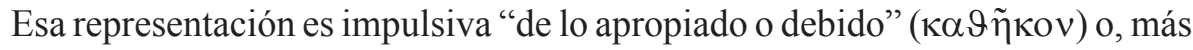
precisamente, de lo que el agente cree que es correcto o apropiado.

Desde el comienzo de este apartado indiqué la relevancia de la noción de asentimiento para comprender el significado de la prescripción "hacer un uso correcto de las representaciones" como una interpretación del dictum socrático "una vida sin examen no es digna de ser vivida por un ser humano". Pero el pasaje clave de Epicteto, donde la noción de asentimiento desempeña, una vez más, un papel decisivo, es el siguiente:

“¿Cuál es la causa de asentir a algo? El hecho de que se [nos] representa-parece ${ }^{22}$

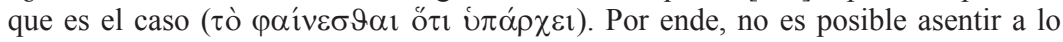
que se representa-parece que no es el caso. ¿Por qué? Porque ésta es la naturaleza

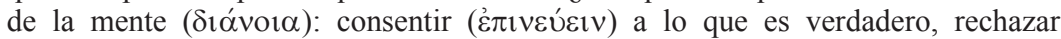
( $\delta v \sigma \alpha \rho \varepsilon \sigma \tau \varepsilon \tilde{i v})$ lo que es falso, suspender el juicio ( $\left.\varepsilon \pi \varepsilon \varepsilon^{\prime} \chi \varepsilon i v\right)$ respecto de lo que no es evidente. ¿Cuál es la prueba de esto? 'Experimenta $(\pi \alpha \dot{\vartheta} \varepsilon)$, si puedes, que es de noche'; no es posible. 'No experimentes ( $\alpha \pi$ ó $\pi \alpha \vartheta \varepsilon)$ que es de día'; no es posible. 'Experimenta o no experimentes que el número de estrellas es par'; no es posible. Por tanto, cuando alguien asiente a lo falso, sábete que no quería asentir a lo falso, pues toda alma está privada de la verdad de modo involuntario (őkov $\sigma \alpha$ ), como dice Platón; ${ }^{23}$ pero le pareció que lo falso era verdadero. Pero vamos, en el caso

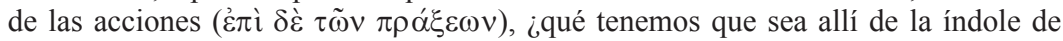
lo verdadero o lo falso? Lo debido y lo que es contrario a lo debido ( $\tau$ ò $\kappa \alpha \vartheta \tilde{\eta} \kappa o v$

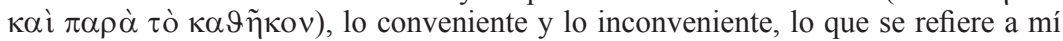
y lo que no se refiere a mí, y todo lo que es semejante a esto. 'Por consiguiente, ¿no puede una persona creer que algo le conviene pero no elegirlo?' No puede, como la que dice: 'Comprendo $(\mu \alpha \nu \vartheta \alpha ́ v \omega)$ que lo que estoy por hacer es malo, pero mi furia $(\vartheta \cup \mu o ́ \varsigma)$ es más poderosa que mis decisiones $(\beta o v \lambda \varepsilon u ́ \mu \alpha \tau \alpha)$ '. ${ }^{24}$ Porque esto

22 En el contexto es muy claro que $\varphi \alpha$ ívє $\sigma \vartheta \alpha \iota$ y sus cognados tiene un doble valor fenoménico-cognitivo, de ahí mi traducción "representa-parece".

23 Se trata de una paráfrasis más o menos libre de Platón, Sofista 228c.

24 Eurípides, Medea vv. 1078-1079. 
mismo, satisfacer su furia y castigar a su esposo, lo considera más conveniente que salvar a sus hijos. Sí, pero se engaña'. Muéstrale claramente que se engaña y no lo hará [más], pero hasta que no se lo muestres, ¿cómo puede seguir a algo si no es a lo que le parece [ser el caso]? A nada [puede seguir si no le parece que es el caso]. [...] Consiguientemente, cualquiera que recuerde esto con claridad, que la medida de toda acción es lo que a una persona le (a)parece ser el caso ( -por lo demás, el '(a)parece' es correcto o incorrecto; si correcto, es irreprochable, si incorrecto, él mismo es castigado pues no puede ser uno el equivocado y otro el perjudicado- no se encolerizará con nadie, no se irritará con nadie, no se enojará con nadie, no censurará a nadie, no odiará a nadie, no se pondrá en guardia con nadie; ¿de manera que los hechos que son tan grandes y terribles tienen este principio,

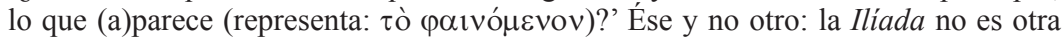
cosa que una representación ( $\varphi \alpha \nu \tau \alpha \sigma i \alpha)$ y un uso de las representaciones $(\chi \rho \tilde{\eta} \sigma \iota \varsigma$ $\varphi \alpha \nu \tau \alpha \sigma i \tilde{\omega} \nu)$ " (Epicteto, Dis. I 28, 1, 1-12, 2; con omisiones).

El argumento puede articularse en los siguientes pasos: $(i)$ el estado

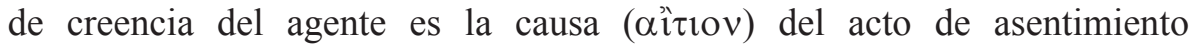
( $\left.\sigma \gamma_{\kappa} \alpha \tau \alpha \tau^{\prime} \vartheta \varepsilon \sigma \vartheta \alpha \imath\right)$, ya que nadie asiente a lo que cree que es falso. La propia naturaleza de la mente ( $\delta ı \alpha ́ v o ı \alpha)$ es consentir a lo que es verdadero, rechazar lo que es falso y suspender el juicio respecto de lo que es no evidente u "opaco" desde el punto de vista cognitivo; pero un acto mental lógicamente anterior a "consentir", "rechazar" y "suspender el juicio" es el "creer", i.e. el estado de creencia en que se encuentra la persona que establece qué es verdadero, qué falso y qué no evidente (i.e. qué es no - evidentemente- verdadero o falso). De aquí se sigue (ii) que quien asiente a lo falso, en realidad, no quería asentir a lo falso (aquí puede leerse, una vez más, un ingrediente intelectualista "socrático" en el argumento de Epicteto). Ese error (teórico pero que, como se ve en el texto, Epicteto hace extensivo al dominio práctico) se debe a que la creencia $\mathrm{y}$, en general, el estado mental involucrado en el proceso de discernimiento de lo verdadero, lo falso y lo indeterminado o no evidente ( $\alpha \delta \eta \lambda \alpha)$ era falsa. En el siguiente paso (iii) Epicteto pasa explícitamente al nivel práctico de consideración, y se pregunta qué es lo verdadero y lo falso en el dominio de la acción (Dis. I 28, 5, 1-2:); la respuesta es que lo verdadero (en el sentido de "verdad práctica", ya que se trata de lo verdadero en el dominio de la praxis) no puede ser otra cosa que "lo debido" ( $\tau$ ò $\kappa \propto \vartheta \tilde{\eta} \kappa o v)$, y lo falso "lo que es contrario a lo debido" ( $\pi \alpha \rho \grave{\alpha} \tau$ ò $\kappa \alpha \vartheta \tilde{\eta} \kappa o v)$, lo conveniente y lo no conveniente, etc.; como es habitual en el estoicismo, este tipo de casos se ejemplifica con Medea, un modelo psicológico oscilante típico que, característicamente, se encuentra en un estado de autoengaño. ${ }^{25}$ Para sacar a Medea del autoengaño el que el agente se muestra vacilante, cambia de opinión permanentemente, oscila entre tomar la decisión 
hay que "mostrarle" que está en el engaño y eso, presumiblemente, solamente puede lograrse mediante un procedimiento de esclarecimiento cognitivo, de manera que un agente de estas características dé cada vez con menor frecuencia asentimiento a las representaciones no cognitivas. En este paso del argumento queda claro también el papel relevante de "lo debido" en la determinación de lo que es correcto (i.e. "verdadero") en el dominio práctico, una idea que sin duda se remonta al estoicismo antiguo, tal como es reportada por Estobeo. ${ }^{26}$ Sugiero que en este pasaje de Estobeo y en el de Epicteto recién citado in extenso la expresión $\tau$ ò $\kappa \alpha \vartheta \tilde{\eta} \kappa o v$ no está usada en el sentido técnico estoico estricto de "acto debido" (es decir,"lo que una vez realizado, comporta una justificación razonable, un acto que la razón elige llevar a cabo, tal como honrar a los padres, a los hermanos, a la patria, compartir la vida con los amigos", actos que no tienen un carácter necesariamente moral), sino de "acto debido perfecto",

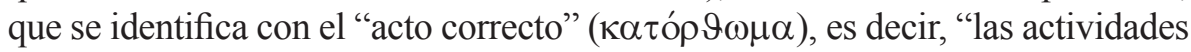
según virtud, como el actuar con prudencia y con justicia". ${ }^{27}$ Lo "debido" debe ser entonces una representación impulsiva, cuyo contenido coincide con un acto debido perfecto o un acto correcto, es decir, un acto debido cuyo contenido es un acto virtuoso. Pero el paso más importante del argumento es el que (iv), retomando la afirmación inicial del pasaje, sostiene que la "medida" ( $\mu$ ć $\tau \rho o v)$ de toda acción es lo que al agente le (a)parece ser el caso. ${ }^{28}$ Pero tal (a)parecer puede ser correcto o incorrecto y, sugiero, la corrección o incorrección del (a)parecer o, más precisamente, el asentimiento o no asentimiento a un (a)parecer correcto o incorrecto depende del estado cognitivo del agente. Eso explica la introducción que, hacia el final del pasaje, hace Epicteto del "uso de las representaciones".

correcta o incorrecta pero, finalmente, siempre toma la incorrecta (Cf. Eurípides, Medea, v. 1078, citado por Crisipo, como nos informa Galeno en DHP III 3, 188, 27-28; IV 6, 270, 10-24; 272, 9-274, 26). Según la explicación estoica, Medea debe haber prestado su asentimiento a una proposición cuyo contenido podría haber sido "lo correcto o apropiado es vengarme de mi marido". Al dar su asentimiento a esta proposición (como finalmente hace) es capaz de darse cuenta de las consecuencias que su acción implica porque, en alguna medida, es consciente del hecho de que está a punto de hacer algo malo: matar a sus propios hijos (Eurípides, Medea, vv. 1078-1080). Esto concuerda perfectamente con la explicación estoica de que todas las pasiones o afectos son violentos, porque los que se encuentran en estados pasionales, emocionales o afectivos $(\pi \alpha ́ \vartheta \eta)$, aunque con frecuencia ven o advierten que no deberían hacer algo, sentir, o ser afectados por algo (dolor o temor, por ejemplo), al ser arrastrados por la violencia de tales estados afectivos, son conducidos a hacerlo o sentirlo de todos modos (Estobeo, Ext. II 89, 6-9-90, 2-6 y mis comentarios en BOERI 2005: 404-405).

26 Ext. II 86, 17-18 (= SVF III 169).

27 Estobeo, Ext. II 85, 13-86, 4; 86, 10-16 (SVF III 494; cf. LS 59B); DL VII 108 (SVF III 495; LS 59E); Estobeo, Ext.II 96, 18-97, 14 (SVF III 501; LS 59M).

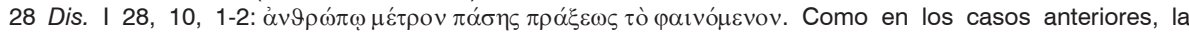
grafía (a)parece intenta apresar el doble carácter de las expresiones griegas $\tau$ ò $\varphi \alpha \imath v o ́ \mu \varepsilon v o v$ y $\varphi \alpha i ́ v \varepsilon \tau \alpha$ : fenoménico ("aparece") y cognitivo ("parece"). 


\section{Uso correcto de las representaciones y criterio de verdad práctica}

Epicteto parece particularmente interesado en acentuar el carácter innato del bien, a punto tal que cuando se da una "representación clara del bien" ( $\alpha \gamma \alpha \vartheta o \tilde{u} \varphi \alpha \nu \tau \alpha \sigma i \alpha \nu$ Ẻv $\alpha \rho \gamma \tilde{\eta})$ el agente no puede más que prestar su asentimiento, lo que en el lenguaje estoico técnico significa asentir a la proposición que expresa el contenido intencional de la representación clara del bien que, como tal, debería ser una representación cognitiva (Dis. III 3, 1-4). Pero Epicteto también puede estar enfatizando la disposición natural que tienen los agentes racionales hacia el bien, y ello en el sentido de que las personas únicamente serán plenamente racionales cuando en el dominio teórico reconozcan el bien como tal y en el práctico obren según el bien. Este enfoque introduce el espinoso tema del innatismo estoico y en particular de la existencia de "preconceptos" $(\pi \rho 0 \lambda \eta \dot{\psi} \psi \varepsilon 1 \varsigma){ }^{29}$ Epicteto está dispuesto a defender la tesis de que los preconceptos son comunes a todos los seres humanos y que, aun cuando lleguemos a la vida careciendo de conceptos teóricos (como el de triángulo rectángulo), no podemos llegar a la vida sin

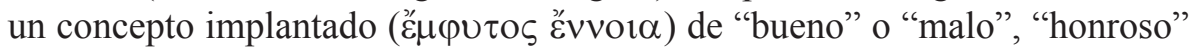
o "vergonzoso", "conveniente" o "inconveniente", etc. Su argumento para justificar esta afirmación no es quizá del todo convincente, ${ }^{30}$ aunque tal vez ayuda a comprender la radicalidad que en su opinión tiene el talante práctico

29 La evidencia textual más relevante sobre el tema se encuentra en Plutarco (Sobre las nociones communes [Noc.]1070 C-D, donde atribuye a Crisipo que nociones evaluativas como "bueno", "malo", "lo que es objeto

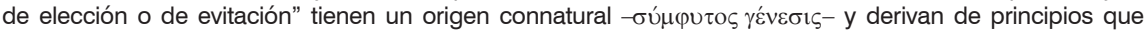
están en nosotros. Véase también Plutarco Contrad. 1042A, donde se argumenta que la discusión sobre los bienes y los males es la más coherente con el modo de vida y la que especialmente está en contacto con los "preconceptos implantados": "̌́ respecto se encuentra también en Alejandro de Afrodisia, Sobre la mezcla 217, 2-4, ed. Bruns.Lo que parece claro es que tanto Crisipo como Epicteto parecen respaldar un cierto innatismo respecto de los conceptos prácticos o evaluativos, no respecto de los teóricos.

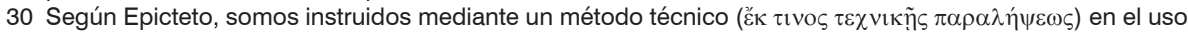
de conceptos teóricos como "triángulo rectángulo" o "semitono"; en efecto, nadie desde el comienzo de su vida hace uso de ellos (y por eso "los que no los conocen tampoco creen conocerlos"). Pero no hay

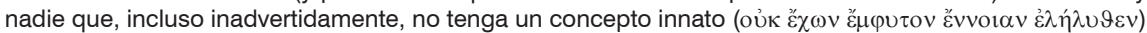
de cosas tales como "bueno" o "malo", porque todos usamos tales nombres e intentamos aplicarlos a los casos particulares, como cuando uno dice "lo hizo bien, de manera debida o indebida; fue desafortunado o afortunado; es justo o injusto". Usamos esos nombres "como si estuviéramos instruidos por la naturaleza"

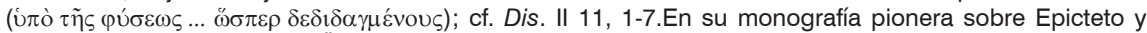
el estoicismo antiguo BONHÖFFER intentó argumentar que las $\pi \rho \circ \lambda \eta ́ \psi \varepsilon \iota \varsigma$ estoicas no dependen de la experiencia sensible, ya que dichos preconceptos se restringen a los conceptos evaluativos (cf. su 1890: 200-203. BONHÖFFER está pensando en Dis. I 18, 6, donde Epicteto argumenta que la vista es capaz

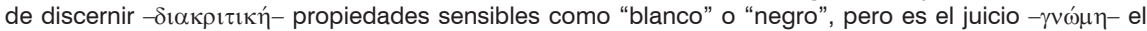
que discierne lo que es bueno o malo (i.e. propiedades evaluativas; para la discusión de estos pasajes cf. BONHÖFFER 1890: 193-195).SANDBACH presentó algunas objeciones importantes a la identificación de BONHÖFFER entre "concepto" y "preconcepto (cf. su 1971: 22-23; 35, n.12). Una discusión actualizada del innatismo estoico se encuentra en SCOTT 1995: 201-207. 
del uso correcto de las representaciones.Una persona es noble y buena, piensa Epicteto, por el hecho de hacer uso de sus representaciones tal y como lo indica la naturaleza, pues toda alma por naturaleza asiente a lo verdadero, rechaza lo falso y suspende el juicio respecto de aquello que no es evidente (Dis.III 3, 1-2 et passim). Si esto es así, el agente se encamina desiderativamente hacia el bien, evita el mal y no hace ninguna de las dos cosas respecto de lo que no es bueno ni malo. Pero para que esta explicación funcione adecuadamente hay que dar por sentado que el agente sabe realmente qué es lo que racionalmente le conviene y cuál es el verdadero objeto de su interés, como vimos antes al comentar el "socrático" pasaje de Dis. II 26, 1.

Como es obvio, la cuestión del asentimiento y del estado cognitivo del agente resulta crucial para explicar de qué modo una persona es capaz de distinguir un bien real de uno aparente. En sus discusiones con los Académicos los estoicos Crisipo y Antípatro parecen haber defendido la tesis de que no hay acción ni impulso sin asentimiento ( $\alpha \sigma 0 \gamma \kappa \alpha \tau \alpha \vartheta \dot{\varepsilon} \tau \omega \varsigma)$, y que los que sostienen que, cuando una apariencia o representación apropiada (oícía $\left.\varphi \alpha \nu \tau \alpha \sigma^{\prime} \alpha\right)$ se hace presente, el impulso inmediatamente sobreviene sin

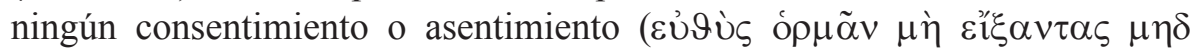

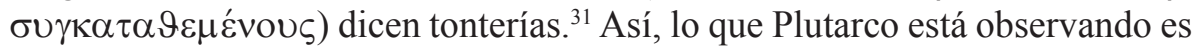
que para los estoicos, después de todo, la mera presencia de la representación apropiada activa el impulso directamente sin que se requiera un asentimiento previo. Para escapar a la contradicción que Plutarco atribuye a Crisipo este pasaje podría interpretarse como si significara que dar asentimiento a una proposición que describe una representación impulsiva del tipo "debo hacer $F$ " es lo mismo que llevar a cabo un impulso de hacer $F$. Hay, sin embargo, un problema de orden sistemático que debe ser enfatizado: lo "apropiado" o

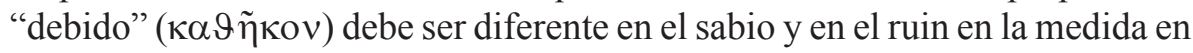
que los estándares que tienen para decidir qué apariencias o representaciones son realmente apropiadas son diferentes, y sus evaluaciones de lo que es bueno o malo pueden discrepar. Tanto el sabio como el ruin reciben representaciones cognitivas y no cognitivas, pero cuando el sabio recibe estas últimas advierte que la proposición que describe el contenido de la representación no es verdadero y no asiente a ella. Esto muestra que la representación impulsiva sólo es condición necesaria de la acción, no suficiente, porque sin asentimiento

31 Plutarco, Contrad. 1057A (SVF III 177; LS 53S). Lo que sigue en el pasaje de Plutarco es parte de su disputa con los estoicos: Plutarco intenta mostrar que Crisipo se contradice al decir que no hay acción ni impulso sin asentimiento y al sugerir más tarde (cf. 1057A-B) que no se requiere ningún asentimiento o consentimiento, sino sólo una acción e impulso hacia lo que aparece. 
no hay acción y el asentimiento depende del agente. Uno tal vez debería preguntarse si puede ocurrir que el ruin se encuentre frente a lo que es propia o realmente bueno y no lo reconozca como tal. Galeno informa una teoría de Crisipo que parece bastante cercana al enfoque de Epicteto: según Crisipo, si un agente considera que lo placentero es bueno y lo doloroso malo, y si sigue su creencia y elige lo primero y evita lo segundo, es "ignorante de la esencia

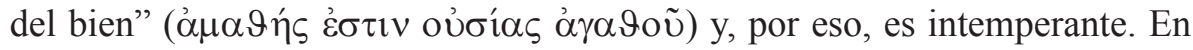
todas nuestras acciones, entonces, elegimos lo que parece ser bueno y evitamos lo que parece ser malo, y por naturaleza poseemos esas tendencias hacia cada una de esas cosas. Pero para hacer correctamente nuestras elecciones y evitaciones necesitamos de la filosofía, cuya función es enseñarnos qué es lo verdaderamente bueno y malo ( En su función terapéutica la filosofía se convierte en el medio por el cual podríamos distinguir el bien aparente del bien real (Galeno, DHP VII 2, 436, 23-29; SVF III 256).

Epicteto ofrece un interesante argumento adicional que ayuda a examinar las diferentes actitudes que los agentes virtuosos y viciosos tienen frente a una "apariencia o representación apropiada". Las personas -argumenta Epictetotoman en serio aquellas cosas que aman de modo apropiado. Solamente toman en serio los bienes; en cambio, no toman en serio ni los males ni lo que no les concierne. Así, pues, si toman en serio los bienes, también los aman. Por lo tanto, cualquiera que conozca lo que es el bien debe amarlo. Por el contrario, quien es incapaz de discriminar lo que es bueno de lo que es malo (y lo que no es ni bueno ni malo) no puede amar. Consecuentemente, amar es únicamente propio del prudente o del sabio ( $\varphi \rho$ óvıно;; Dis. II 22, 1-3). La razón por la que el ruin no puede distinguir entre el bien y el mal es que, al no hacer un uso correcto de sus sentidos y al no discriminar correctamente sus

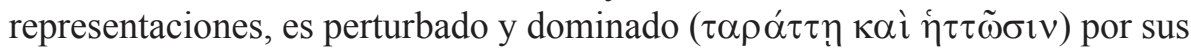
representaciones (o apariencias) y por su persuasividad. El efecto inmediato es que cree, primero, que $x$ es bueno, luego, que ese mismo $x$ es malo, más tarde que no es ni malo ni bueno. En términos socráticos, este agente está siendo dominado por el poder de la apariencia, que lo hace cambiar de opinión acerca de lo mismo, remueve su tranquilidad y fomenta su inestabilidad de carácter y falta de decisión (Dis. II 22, 5-7; II 22, 25; esta descripción de Epicteto del agente vicioso evoca la del Sócrates platónico del Protágoras 356d1-e2). Por el contrario, la persona que tiene sus capacidades cognitivas correctamente entrenadas también tendrá su carácter bien dispuesto, y advertirá que el bien del hombre es su $\pi \rho o \alpha i ́ p \varepsilon \sigma ı \varsigma$ bien dispuesta (Dis. I 8, 16; I 29, 1). La tesis que yace detrás de esta explicación es que uno tendrá una vida práctica de buena 
calidad si y sólo si hace un uso correcto de sus representaciones o apariencias, ${ }^{32}$ que es lo único que, en sentido estricto, depende del agente. Los seres humanos no podemos eliminar las apariencias o representaciones de nuestras vidas; lo que sí podemos hacer es examinarlas, de manera de rechazar aquellas que no pasen el examen de la razón. Epicteto sostiene que la naturaleza nos ha dotado de razón para hacer un uso correcto de las representaciones, y hacer un uso correcto de las representaciones no es otra cosa que someterlas a prueba, distinguirlas y no asentir a ninguna que no haya sido sometida a prueba (Dis. I $20,5-8)$.

Nada indica que uno debe ser necesariamente bueno o malo; por el contrario, el propio estado del carácter (o $\pi \rho \circ \alpha i \rho \varepsilon \sigma i \varsigma$, que exhibe lo que los humanos son como agentes que se definen propiamente en términos de sus propios actos volitivos) depende de cada persona. ${ }^{33}$ El lugar que las cosas externas ( $\tau \grave{\alpha} \hat{\varepsilon} \kappa \tau$ ó $\varsigma$ ) tienen para Epicteto muestra el modo en el que la propia $\pi \rho \circ \alpha i ́ \rho \varepsilon \sigma ı \varsigma$ debería funcionar para alcanzar el bien real y, por ende, para tener una vida de buena calidad. Las cosas externas son los materiales ( $\tilde{\tilde{v}} \lambda \alpha \imath)$ de nuestra elección: dependiendo del modo en que la propia elección se comporte el agente alcanzará su propio bien o su propio mal. Pero el único modo a través del que la elección alcanzará el propio bien es no teniendo una especial consideración por dichos materiales: si las propias creencias ( $\delta$ ó $\mu \alpha \tau \alpha)$ respecto de esos materiales son correctas, harán nuestra elección buena, si son perversas y distorsionadas, la harán mala (Dis. I 29, 2-4). Además, Epicteto argumenta que la tarea de un agente racional que está haciendo algún progreso en su vida moral radica en tres factores: ( $i$ ) en el deseo y el rechazo (ỏ

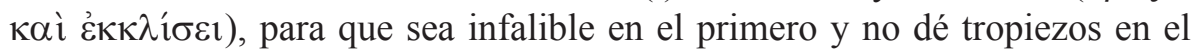

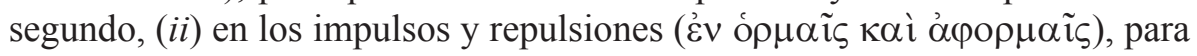
no caer en el error, y (iii) en el asentimiento y la suspensión del juicio ( $\dot{\varepsilon} \mathrm{V}$

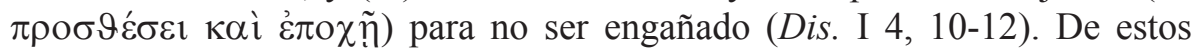
requerimientos, el más importante y urgente, observa Epicteto, es el primero, pues las pasiones surgen cuando se frustra el deseo o cuando el agente cae en lo que rechaza (Dis. III 2, 3; de hecho, el origen de una emoción se explica por el hecho de que uno quiere que algo suceda y que tal hecho no resulte tal como uno quiere; I 27, 10-11). Sin duda, deberíamos suponer que los otros dos requisitos también contribuyen de un modo importante a que no surjan los

32 VéaseDis.I 1, 7; I 1, 12; I 6, 13; I 20, 5. Incluso la determinación de la "esencia del bien" depende en cierto modo del uso de las apariencias o representaciones (cf. Dis. II 1, 4; II 8, 7-8). Sobre el uso de las representaciones en Epicteto cf. la pormenorizada discusión de LONG 1996: 275-281 y, más recientemente, 2002: 85 , y 214-217.

33 Cf. LONG 2002: 28-29; 218-220. 
estados emocionales, pues la evaluación correcta del impulso y la repulsión -que deberían traducirse en un impulso a actuar o no actuar en una dirección determinada- $\mathrm{y}$, en conexión con esto, la evaluación del asentimiento y la suspensión del juicio (que evita que seamos engañados por lo que no es claro) suministran al agente los recursos apropiados para tener creencias basadas en conocimientos, i.e. creencias firmes, confiables y constantes.

\section{Epílogo: Epicteto, ¿el socrático?}

Queda todavía una última pregunta: si el ruin estoico es, como el perverso socrático, ignorante, ¿qué puede hacer para ser consciente de su propio estado de ignorancia? Según Epicteto, una tarea peculiar del bueno es tratar con sus apariencias o representaciones del modo apropiado, i.e. "de acuerdo con la naturaleza" (Dis. III 3, 1), lo cual debe significar "haciendo un uso correcto" de tales representaciones luego de someterlas a un preciso análisis racional. Pero para hacer eso uno ya tiene que ser sabio en sentido estoico; si no es así, habrá que presuponer que la propia evaluación de la representación puede ser deficiente. Epicteto hace notar que tal como está en la naturaleza de toda

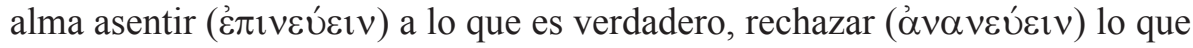

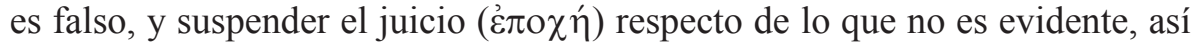
también el alma del agente debe ser desiderativamente puesta en movimiento hacia el bien ( $\pi \rho$ ò $\varsigma \mu \grave{\varepsilon} v \tau$ ò $\alpha \gamma \alpha \vartheta$ òv ỏ $\rho \varepsilon \kappa \tau \imath \kappa \tilde{\omega} \varsigma \kappa \imath v \varepsilon \tilde{\imath} \sigma \vartheta \alpha \imath$ ), debe rechazar el mal y lo que no es ni malo ni bueno. Epicteto también cree que cuando el bien se representa o aparece al agente, inmediatamente activa su alma hacia él, en tanto que cuando lo que aparece es el mal el alma se aparta de él: la propia alma nunca rechazará "una representación clara del bien" ( $\alpha \gamma \alpha \vartheta \circ \tilde{u} \varphi \alpha \nu \tau \alpha \sigma i ́ \alpha$

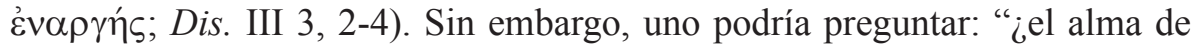
quién?" Si Epicteto quiere decir el alma del sabio, no hay ninguna dificultad, pero si cree que esto es así con respecto a cualquier alma (incluyendo la del ruin, claro está), el asunto parece problemático. Sin duda, es necesario tener las propias creencias acompañadas de conocimiento para no rechazar una representación clara del bien. Como ya he señalado, tal vez Epicteto sólo está subrayando la disposición natural que los seres racionales tienen hacia lo que es bueno en la medida en que, en su opinión, todo el mundo nace dotado de una concepción innata de lo que es bueno y malo (Dis. II 11, 3-4), y esto es de tal manera que los agentes serán realmente racionales cuando reconozcan lo que es bueno en el nivel teórico y actúen correctamente en el nivel práctico. Lo que parece ser más o menos claro es que hay una relación esencial entre el bien como objeto de impulso y el bien como objeto de conocimiento. Pero 
la apariencia o representación del bien real es la única que es capaz de poner en movimiento el impulso correcto, un impulso que se traduce en una acción virtuosa.

Parece al menos extraño tener alguna razón para sospechar que de la (aparentemente) inocente afirmación "una vida sin examen no es digna de ser vivida para el ser humano" (Platón, Apología 38a) pueda seguirse toda la parafernalia que, según Epicteto, significa la sentencia socrática. Sin embargo, si lo que he sugerido en este ensayo es al menos plausible, uno tendría que hacer un esfuerzo más amplio y tratar de entender que en los s. I-II d.C. Sócrates seguía vivo, ya que sus ideas seguían siendo discutidas o, más aún, reinterpretadas con trasfondos que, aunque a Sócrates no podían siquiera habérsele ocurrido, eran exigidos por los contextos sistemáticos estoicos de los que parte Epicteto. A la pregunta de si Epicteto puede considerarse como un "socrático" respondo que "sí", aunque ser un socrático no puede entenderse en el sentido de alguien que suscribe a todo lo que, supuestamente, dice Sócrates (i.e. el Sócrates de los diálogos de Platón), sino más bien en el sentido de un filósofo que elabora y reinterpreta lo que comprende y cree que debió ser el pensamiento de Sócrates, de modo que dicho pensamiento pueda ser funcional a su propia filosofía.

\section{Referencias bibliográficas}

ALESSE, F. 2000. La stoa e la tradizione socratica, Napoli: Bibliopolis.

ARNIM, I. von, (ed.) 1903-1905. StoicorumVeterum Fragmenta, Leipzig: Teubner(4 vols.; citado $S V F)$.

BOERI, M.D. 2004. "Socrates, Aristotle, and the Stoics on the apparent and real good”, en J. J. Cleary, G. Gurtler (eds.) Proceedings of the Boston Area Colloquium in Ancient Philosophy, vol. XX, Leiden: Brill, 109-141.

BOERI, M.D. 2005."The Presence of Socrates and Aristotle in the Stoic Account of akrasia", en R. Salles (ed.) Metaphysics, Soul and Ethics. Themes from the Work of Richard Sorabji, Oxford: Oxford University Press, 383-412.

BONHÖFFER, A. 1890. Epictet un die Stoa. Untersuchungen zur stoischen Philosophie, Stuttgart :Verlag von Ferdinand Enke.

BRENNAN, T. 2003. "Stoic Moral Psychology", en B. Inwood (ed.) The Cambridge Companion to The Stoics, Cambridge: Cambridge University Press, 257-294.

BRICKHOUSE, T.C., SMITH, N.D. 2000. The Philosophy of Socrates, Boulder, Colorado: Westview Press.

BRICKHOUSE, T.C., SMITH, N.D. 2010.Socratic Moral Psychology, Cambridge: Cambridge University Press.

COOPER, J.M. 1999. Reason and Emotion. Essays on Ancient Moral Psychology and Ethical Theory, Princeton, New Jersey: Princeton University Press. 
DeFILIPPO, J.D., MITSIS, P.T. 1994. "Socrates and Stoic Natural Law", en Vander Waerdt, P.A. (ed.) 1994.The Socratic Movement, Ithaca and London: Cornell University Press, 252-271.

DRAGONA-MONACHU, M. 2007. "Epictetus on freedom: Parallels between Epictetus and Wittgenstein", en A. S. MASON\& T. SCALTAS, (eds.). The Philosophy of Epictetus, Oxford-New York : Oxford University Press, 112-139.

FILLION-LAHILLE, J. 1984. Le De ira de Sénèque et la philosophie stö̈cienne des passions,Paris : Klincksieck.

GIANNANTONI, G. 1990. Socratis et socraticorum reliquiae, Napoli: Bibliopolis.

GÓMEZ-LOBO, A. 1998. La Ética de Sócrates, Barcelona/Buenos Aires/México D.F./Santiago de Chile: Ed. Andrés Bello (versión adaptada de la edición española de 1989, FCE - editada en México-e inglesa de 1994, Ed. Hackett).

GÓMEZ-LOBO, A. 2004. Platón. Menón, Santiago: Ed. Universitaria.

GÖRLER, W. 1977. "Asthenes sunkatathesis. Zur stoischen Erkenntnistheorie”, en Würzburger Jahrbücher für die Altertumswissenschaft neue Folge, Band 3, 83-92.

HÜLSER, K. Die Fragmente zur Dialektik der Stoiker, Stuttgart-Bad Cannstatt 1987$1988(4$ vols. $=F D S)$.

IERODIAKONOU, K. 2007. "The Philosopher as a God's Messenger", en A. S. MASON\& T. SCALTAS, (eds.). The Philosophy of Epictetus, Oxford-New York: Oxford University Press, 56-70.

INWOOD, B. 1985.Ethics and Human Action in Early Stoicism, Oxford: Oxford University Press.

IOPPOLO, A.M., 1980. Aristone di Chio e lo stoicismo antico, Napoli: Bibliopolis. IOPPOLO, A.M. 1995. "L' Horme Pleonazousa nella dotrinna stoica della passione", Elenchos, Anno 16, 1, 25-55.

LONG, A.A., SEDLEY, D.N. 1987. The Hellenistic Philosophers, Cambridge: Cambridge University Press (2 vols.; citado LS).

LONG, A.A. 1996. Stoic Studies, Cambridge: Cambridge University Press.

LONG, A.A. 1999. "The Socratic Legacy", en Algra, K., Barnes, J., Mansfeld, J., Schofield, M. (eds.) The Cambridge History of Hellenistic Philosophy, Cambridge: Cambridge University Press, 617-641.

LONG, A.A. 2002. Epictetus. A Stoic and Socratic Guide to Life, Oxford: Oxford University Press.

SALLES, R. 2005. The Stoics on Determinism and Compatibilism,London: Ashgate. SALLES, R. 2007. "Epictetus on Moral responsibility for Precipitate Action", en BOBONICH, C., DESTRÉE, P. (eds.) Akrasia in Greek Philosophy. From Socrates to Plotinus, Leiden-Boston: Brill, 249-263.

SANDBACH, F. H. 1971. 'Ennoia and Prolepsis in the Stoic Theory of Knowledge', in A.A. Long (ed.) Problems in Stoicism, London: Athlone Press, 22-37.

SCOTT, D. 1995. Recollection and Experience. Plato's Theory of Learning and its successors, Cambridge-New York: Cambridge University Press. 
SCHENKL, H. 1965. Epicteti Dissertationes ab Arriani Digestae, Stuttgart: Teubner (reimpr.; ed. original 1916).

SCHOFIELD, M. 1984. "Ariston of Chios and the Unity of Virtue", en Ancient Philosophy, 4, 83-96.

SEDLEY, D.N. 1993. "Chrysippus on Psychological Causality", en J. Brunschwig, M. C. Nussbaum (eds.) Passions and Perceptions. Studies in Hellenistic Philosophy of Mind (Proceedings of the Fifth Symposium Hellenisticum), Cambridge 1993, 313331

STRIKER, G. 1994. "Plato's Socrates and the Stoics", en P. A. VANDER WAERT (1994), 241-251.

VANDER WAERT, P.A. (ed.) 1994. The Socratic Movement, Ithaca and London: Cornell University Press.

WACHSMUTH, C. 1884, Ioannis Stobaei Anthologiilibri duo priores qui inscribisolent Eclogaephysicae et ethicae, Berlin: Weidmann. 